УДК 621.396 .96

\title{
АДАПТИВНАЯ ОБРАБОТКА СИГНАЛОВ НА ФОНЕ КОМБИНИРОВАННЫХ ПОМЕХ
}

\author{
АНДРЕЕВ В. Г., НГУЕН Т. Ф. \\ Рязанский государственный радиотехнический университет, \\ Россия, Рязань, 390005, ул. Гагарина, д. 59/1
}

\begin{abstract}
Аннотация. Подавление комбинированных помех является одной из важнейших задач обработки радиолокационных сигналов. Показано, что предлагаемый алгоритм разбиения вектора обработки на подвекторы коэффициентов нерекурсивного фильтра подавления помех, позволяет увеличить среднюю по доплеровским скоростям сигнала вероятность правильного обнаружения на 6-28\% по сравнению с известным неадаптивным обеляющим фильтром. Предлагаемый алгоритм не требует обращения корреляционной матрицы помех при изменении мощности некоррелированной мешающей компоненты, что сокращает в 1,8-7 раз вычислительные затраты на его реализацию по сравнению с оптимальным адаптивным алгоритмом
\end{abstract}

Ключевые слова: адаптивная обработка сигналов; цифровая обработка сигналов; комбинированные помехи; фильтрация

Для работы радиотехнических систем характерно воздействие комбинированных (комплекс коррелированных и некоррелированных) помех, которые, поступая на вход приемника вместе с полезными сигналами, затрудняют их обнаружение. Например, для систем управления воздушным движением, расположенных в аэропортах и на аэродромах типичным является одновременное присутствие на входе приемного устройства мешающих отражений от подстилающей поверхности и активных шумовых помех (АШП) от различных источников (наземное и бортовое радиооборудование, промышленные помехи и т.д.). Борьба с такими мешающими процессами заключается в обелении коррелированной компоненты до уровня шума. Проблема заключается в том, что его уровень может существенно изменяться за счет вариаций коэффициента усиления антенны в направлении на источник АШП при сканировании.

Оптимальное решение предполагает для оценки параметров обеляющего помехи фильтра пересчет коэффициентов обратной корреляционной матрицы помех при изменении уровня мощности шумовой составляющей. Известное решение заключается в сохранении прежних значений вектора обработки, т.е. не предполагает адаптацию к изменяющейся мощности АШП, что характерно для режекторных фильтров [1].

Оптимальное решение сопряжено со значительными вычислительными затратами (количество арифметических операций), а известное неадаптивное приводит к недоиспользованию потенциальных возможностей по обнаружению сигналов на фоне комбинированных помех. 